\title{
Application of synchrotron radiation for measurement of iron red-ox speciation in atmospherically processed aerosols
}

\author{
B. J. Majestic, J. J. Schauer, and M. M. Shafer \\ Environmental Chemistry and Technology Program, University of Wisconsin - Madison, 660 N. Park St., Madison, WI \\ 53706, USA
}

Received: 10 January 2007 - Published in Atmos. Chem. Phys. Discuss.: 29 January 2007

Revised: 17 April 2007 - Accepted: 25 April 2007 - Published: 14 May 2007

\begin{abstract}
In this study, ambient atmospheric particulate matter samples were collected using a size-resolved impactor sampler from three urban sites. The purpose of this study is to gain a better understanding of transformations of aerosolbound iron as it is processed in the atmosphere. Thus, the aerosol samples were artificially aged to represent long-term transport (10 to 40 days) or short-term transport (1 to 10 days) and were measured for iron at several time points. At each time point, iron was measured in each size fraction using three different techniques; 1) inductively coupled plasma-mass spectrometry (ICPMS) for total iron, 2) x-ray absorbance near edge structure (XANES) spectroscopy for the measurement of total $\mathrm{Fe}$ (II) and $\mathrm{Fe}$ (III), and 3) a wetchemical method to measure soluble $\mathrm{Fe}(\mathrm{II})$ and $\mathrm{Fe}(\mathrm{III})$. Prior to aging, the XANES spectroscopy results show that a majority ( $>60 \%$ for each size fraction) of the total iron in the $\mathrm{PM}$ is in the form of $\mathrm{Fe}(\mathrm{III})$. Fe(III) was shown to be a significant fraction of the soluble iron (sometimes $>50 \%$ ), but the relative significance of $\mathrm{Fe}$ (III) was found to vary depending on the site. Overall, the total soluble iron depended on the sampling site, but values ranged from less than $1 \%$ up to about $20 \%$ of the total iron. Over the course of the 40 day aging period, we found moderate changes in the relative $\mathrm{Fe}(\mathrm{II}) / \mathrm{Fe}$ (III) content. A slight increase was noted in the coarse $(>2.5 \mu \mathrm{m})$ fraction and a slight decrease in the 0.25 to $0.5 \mu \mathrm{m}$ fraction. The soluble fraction generally showed (excepting one day) a decrease of soluble $\mathrm{Fe}$ (II) prior to 10 days of aging, followed by a relatively constant concentration. In the short-term transport condition, we found that the sub-micron fraction of soluble Fe(II) spikes at 1 to 3 days of aging, then decreases to near the initial value at around 6 to 10 days. Very little change in soluble Fe(II) was observed in the super-micron fraction.
\end{abstract}

Correspondence to: J. J. Schauer

(jschauer@engr.wisc.edu)

\section{Introduction}

Iron has proven to be a key element for the cycling of bulk components in atmospheric particulate matter (Conklin and Hoffmann, 1988; Zuo and Hoigne, 1994). In general, the release of hydroxyl radicals in aqueous aerosol extracts has been correlated to water-soluble iron concentration (Arakaki et al., 2006; Donaldson et al., 1997) which can lead to oxidation of other aerosol species such as sulfur (as $\left.\mathrm{SO}_{2}\right)$ (Faust and Hoffmann, 1986). The cycling of organic matter can also be affected by the chemical form of iron. Zuo and Deng (1997) have shown that the photo-catalytic decomposition of oxalic acid, a common component in atmospheric aerosols, is more efficiently driven by $\mathrm{Fe}$ (III), as compared to $\mathrm{Fe}(\mathrm{II})$ (Zuo and Deng, 1997).

Results of a study performed by Zhuang et al. (1992) reveal that significant amounts of soluble Fe(II) can be found in remote marine aerosols. In addition, this study indicates that iron in atmospheric particles which are transported over long distances may undergo oxidation and reduction transformations in which $\mathrm{Fe}$ (II) and $\mathrm{Fe}$ (III) can be inter-converted. As atmospheric aerosols are generally complex, intra-mixed species containing a variety of organic and inorganic species, it is extremely difficult to predict how the red-ox active transition metals will behave in atmospheric particulate matter (PM). Laboratory studies on iron-containing particles have shown that the oxidation and reduction of $\mathrm{Fe}(\mathrm{II})$ and $\mathrm{Fe}(\mathrm{III})$ species in atmospheric PM can depend on many factors including the electron donors present and the $\mathrm{pH}$. One study revealed that a formate solution is most effective for the photoreduction of $\mathrm{Fe}(\mathrm{III})$ when compared to other common electron donors such as acetate and butyrate (Pehkonen et al., 1993). This study also found that the different chemical form of $\mathrm{Fe}(\mathrm{III})$ (e.g. hematite or amorphous $\mathrm{Fe}(\mathrm{OH})_{3}$ ) is an important determining factor in the rate of photolysis. The red-ox chemistry of iron has been shown to be an integral part of the sulfur cycle (Conklin and Hoffmann, 1988). One study

Published by Copernicus Publications on behalf of the European Geosciences Union. 
performed by Zhu et al. found that aerosols which are high in inorganic sea salt components (chloride, nitrate, and sulfate) tend to resist the photo-reduction of $\mathrm{Fe}$ (III) to $\mathrm{Fe}$ (II) during atmospheric transport (Zhu et al., 1993).

Quantification of iron into $\mathrm{Fe}$ (II) and $\mathrm{Fe}$ (III) in atmospheric particles has been achieved using a multitude of techniques including HPLC (Zhuang et al., 1992), complexation methods (Donaldson et al., 1997; Valavanidis et al., 2000), ion chromatography, and Mössbauer spectroscopy (Hoffmann et al., 1996; Hoffmann et al., 1994). Aside from Mössbauer spectroscopy, all of these techniques are wetchemical techniques and require the iron to be extracted into an aqueous solution. These studies show that, despite the relatively high solubility of $\mathrm{Fe}$ (II) compared to $\mathrm{Fe}$ (III), $\mathrm{Fe}$ (II) was often just a minor component of the soluble iron fraction with the $\mathrm{Fe}(\mathrm{II})$ in the soluble fraction ranging from below the detection limit up to about $15 \%$ of the total soluble iron. The $\mathrm{Fe}$ (II) content in fog and cloud water, however, was shown to have a much greater Fe(II) content ranging from 20 up to $90 \%$. This difference may be due to the $\mathrm{pH}$ of cloud water versus atmospheric PM (Jacob et al., 1985; Kieber et al., 2005).

Of the techniques used to quantify $\mathrm{Fe}(\mathrm{II})$ and $\mathrm{Fe}$ (III) in atmospheric PM, Mössbauer spectroscopy is the only method which can directly measure the chemical speciation, however significant sample mass is needed, which makes application of this technique to ambient and personal PM exposure samples extremely difficult. Other techniques, such as $\mathrm{x}$-ray absorption near edge structure (XANES) spectroscopy and extended $x$-ray absorption fine structure (EXAFS), can be used to directly measure the oxidation state of a metal in a solid matrix and requires no wet-chemical extraction step. XANES and EXAFS have both been used to determine the oxidation states of iron in environmental samples and in the emissions from atmospheric pollution sources (Torok et al., 1994; Zaw et al., 2002), where analyte concentrations are elevated. However, work addressing the oxidation state of transition metals in atmospheric samples using these techniques has not been reported. It is currently known that iron can be inter-converted between $\mathrm{Fe}$ (II) and $\mathrm{Fe}(\mathrm{III})$ in ambient aerosols however, the time-scales of these processes have not been studied. Using atmospheric PM collected from three different urban locations, in this study we investigate the processing of iron in the atmosphere. The aerosols are artificially aged in a tightly regulated temperature, relative humidity, and light environment where the total iron, total Fe(II) and $\mathrm{Fe}(\mathrm{III})$, and soluble $\mathrm{Fe}(\mathrm{II})$ and $\mathrm{Fe}$ (III) are measured as a function of exposure time.

\section{Materials and methods}

\subsection{Sampling}

Size-fractionated PM10 (atmospheric particles with an aerodynamic diameter $<10 \mu \mathrm{m}$ ) samples were collected for two days each in East St. Louis, IL, Los Angeles, CA, and Waukesha, WI. The East St. Louis site is a US EPA-funded Supersite and is in an urban residential/light commercial area is about $3 \mathrm{~km}$ east of St. Louis, MO (Bae et al., 2004). Waukesha, WI is approximately $20 \mathrm{~km}$ west of Milwaukee, WI and the site is on a four-lane suburban road. The site is fenced in and the samplers were raised to fence level approximately $2.5 \mathrm{~m}$ above the ground. The area is a mix of residences and heavy industry, and the site itself is adjacent to an automobile body shop (Sheesley et al., 2005). The Los Angeles site is located in the Los Angeles Basin at the Rancho Los Amigos Medical Research Center facility. This site is dominated by mobile sources and is known to have some of the highest PM10 levels in the US, often exceeding the National Ambient Air Quality Standards (NAAQS) of $150 \mu \mathrm{g} \mathrm{m}^{-3}$ (Singh et al., 2002).

For PM collection, four co-located Sioutas personal cascade impactor samplers (PCIS) (Misra et al., 2002; Singh et al., 2003) were used, each operated at $9 \mathrm{Lpm}$ for $24 \mathrm{~h}$. This sampler separates the PM into five different size fractions: $>2.5 \mu \mathrm{m}, 2.5-1 \mu \mathrm{m}, 1-0.5 \mu \mathrm{m}, 0.5-0.25 \mu \mathrm{m}$, and $<0.25 \mu \mathrm{m}$. In three of the samplers, Teflon (Zefluor, $3.0 \mu \mathrm{m}$ pore size) impactor substrates were utilized. In the fourth sampler, high purity aluminum foil substrates $(99.9995 \%$ metals basis, Alfa Aesar) were used. In all samplers, the after filter was a $37 \mathrm{~mm}$ Telfon (Teflo, $2.0 \mu \mathrm{m}$ pore size) substrate. Particulate matter samples collected on the Teflon and aluminum substrates were placed in acid-cleaned Petri dishes, sealed with Teflon tape, double bagged under nitrogen, and stored in a cooler for shipment to UW-Madison.

Trace-metal clean techniques were used throughout the substrate preparation, particulate matter collection, sampling handling, and analysis phases. All pre- and post- sampling handling of the substrates were performed in a dedicated trace-metal clean room. Before use, all collection substrates were subjected to rigorous acid-washing protocols, which have been show to minimize trace-metal contamination. For Teflon materials, this procedure includes a series of three rinses: trace-metal grade hydrochloric acid (Fisher), tracemetal grade nitric acid (Fisher), followed by $>18.0 \mathrm{M} \Omega$ water. Prior to sampling, the aluminum substrates were rinsed and sonicated in dichloromethane followed by methanol. All substrates were conditioned in a constant temperature and relative humidity environment for at least $24 \mathrm{~h}$ and weighed on a microbalance pre- and post-sampling. 


\subsection{Aerosol aging}

In a Class 50 (ISO Class 4.5) trace-metal clean room, the substrates were cut into sections using either a ceramic knife or ceramic scissors. For each size fraction on each sampling day, the Teflon filters ( $25 \mathrm{~mm}$ Zefluor and $37 \mathrm{~mm}$ Teflo) were cut in half while the aluminum foil substrates were cut into fourths. This resulted in six identical Teflon and four identical aluminum substrates for each size fraction (no aluminum substrates were used for the after filter) for each day. One aluminum quarter and one Teflon half were immediately placed in a dark, nitrogen atmosphere at $-20^{\circ} \mathrm{C}$. This corresponds to the Time $t=0$ day time point. The other samples were placed in acid-cleaned polystyrene Petri dishes with the cover removed and were artificially aged in a tightly controlled temperature $\left(20.7 \pm 0.2^{\circ} \mathrm{C}\right)$, relative humidity $(42.8 \pm 1.1 \%)$ and light $(250 \mu$ Einsteins, $16 \mathrm{~h}$ on, $8 \mathrm{~h}$ off) environment at the Biotron at the UW-Madison for varying aging times. The East St. Louis and the Los Angeles filters were selected to represent long-term aerosol transport and were aged for periods of $0,10,20$, and 40 days. The Waukesha, WI aerosols were selected to represent short-term aerosol transport and were aged for $0,1,3,6$, and 10 days.

Air conditioners supply the building with filtered air $(95 \%$ removal of particles $10-0.3 \mu \mathrm{m}$ ), with another $95 \%$ bag filter at the inlet of the experimental room. We installed additional particle filters on the air discharge vents in the chamber. Overall, the air in the room is supplied with $95 \%$ recycled air and 5\% outside air and the room air was exchanged approximately every $30 \mathrm{~s}$. The filters were transparent to gaseous pollutants, so maximum ozone levels in the room would be around the average outside levels (around $75 \mathrm{ppb}$ ); however the actual value is likely lower as significant ozone degradation in the ventilation system is expected. Illumination of the samples was achieved using a carefully calibrated mix of fluorescent and incandescent light bulbs. The light output from the combination of these bulbs was similar to the solar spectrum, with some excess light in the near infrared region. The spectra from each type of light bulb can be found in the supplementary material (http://www.atmos-chem-phys. net/7/2475/2007/acp-7-2475-2007-supplement.pdf).

For each stage, total iron was measured by high resolution - ICPMS by using $1 / 2$ of a Teflon filter digested using a low-volume microwave-assisted (maximum power $=1000 \mathrm{~W}$ ) acid digestion. At each time point and each size fraction, iron $\mathrm{L}_{\mathrm{II}}$ and $\mathrm{L}_{\mathrm{III}}$ edge XANES spectra were acquired from the aluminum substrates on the high energy and resolution monochromator (HERMON) beamline Synchrotron Radiation Center (SRC). In parallel with the XANES measurement of total $\mathrm{Fe}(\mathrm{II}) / \mathrm{Fe}$ (III), soluble $\mathrm{Fe}(\mathrm{II})$ and $\mathrm{Fe}(\mathrm{III})$ was determined from the Teflon sections using the Ferrozine method as applied to atmospheric aerosols (Majestic et al., 2006) at each time point. Previous work has shown that the soluble fraction of $\mathrm{Fe}$ (II) does not significantly change over the timeframe of this experiment while the PM is stored in the dark at $-20^{\circ} \mathrm{C}$ (Majestic et al., 2006). Therefore, any change in the iron speciation over the course of this experiment is due to the exposure of PM to the artificial atmosphere.

\subsection{Total iron determination}

Total iron measurements were achieved using a low-volume microwave-assisted digestion method shown to minimize trace-metal contamination followed by analysis by inductively coupled plasma-mass spectrometry (ICPMS). The polymethylpentene support ring from the Teflo filter is removed and the filter membrane is placed in a Teflon digestion bomb with a mixture of high purity acids $(1.5 \mathrm{~mL}$ $16 \mathrm{~N} \mathrm{HNO}_{3}, 0.5 \mathrm{~mL} 12 \mathrm{~N} \mathrm{HCl}, 0.2 \mathrm{~mL} 28 \mathrm{~N} \mathrm{HF}$ ). Solubilization of the PM was achieved by subjecting the sealed Teflon bombs to a programmed microwave digestion (Ethos, Milestone) $\left[9 \mathrm{~min}\right.$ temperature ramp to $180^{\circ} \mathrm{C}$ followed by a $10 \mathrm{~min}$ hold at $180^{\circ} \mathrm{C}$ ] and diluted to $30 \mathrm{~mL}$ with $>18.0 \mathrm{M} \Omega$ water. A typical analytical batch consisted of 22 unknowns, 6 standard reference materials (SRMs), 4 matrix blanks, 2 method blanks, and 2 matrix spikes. These included the National Institute of Standards and Technology (NIST) SRMs: Recycled Auto Catalyst (SRM \#2556), Urban Dust (SRM \#1649a), and San Joaquin Soil (SRM \#2709). More details of the method can be found elsewhere (Lough et al., 2005)

\subsection{Total $\mathrm{Fe}(\mathrm{II})$ and $\mathrm{Fe}(\mathrm{III})$ determination}

XANES data were collected at the Synchrotron Radiation Center (SRC), operated, in part by the University of Wisconsin - Madison, in Stoughton, WI on the high energy and resolution monochromator (HERMON) beamline. Initial beam current was approximately $280 \mathrm{~mA}$ and the electron energy was constant at $800 \mathrm{MeV}$. Experiments were performed under ultra-high vacuum (UHV) conditions $\left(\sim 10^{-10}\right.$ torr) using a total electron yield (TEY) detection apparatus. Spectra were obtained at $0.33 \mathrm{eV}$ intervals in replicates of 10 across a scan range that included the zero-valent Fe $\mathrm{L}_{\mathrm{II}}(719.9 \mathrm{eV})$ and $\mathrm{L}_{\text {III }}(706.8 \mathrm{eV})$ edges and were normalized against a gold mesh current to account for beam decay.

There are currently no well-established methods for performing UHV XANES spectroscopy on ambient atmospheric particulate matter. The choice of both particulate matter sampler and substrate are critical for successful UHV TEY analysis. We found that the Sioutas personal cascade impactor sampler (Singh et al., 2002) was ideal for this application as it concentrates the particulate into a narrow line $(1-2 \mathrm{~mm})$ at which the x-ray beam can be focused. In terms of the collection substrate, we determined in our preliminary studies that the particulate matter must be collected on a substrate with the following attributes, if direct analysis on the substrate is sought: Conducting, smooth surface, low interference with target species, and compatible with particulate matter samplers. Teflon filters are commonly used for trace metal collection and, while Teflon is not a conducting material, 


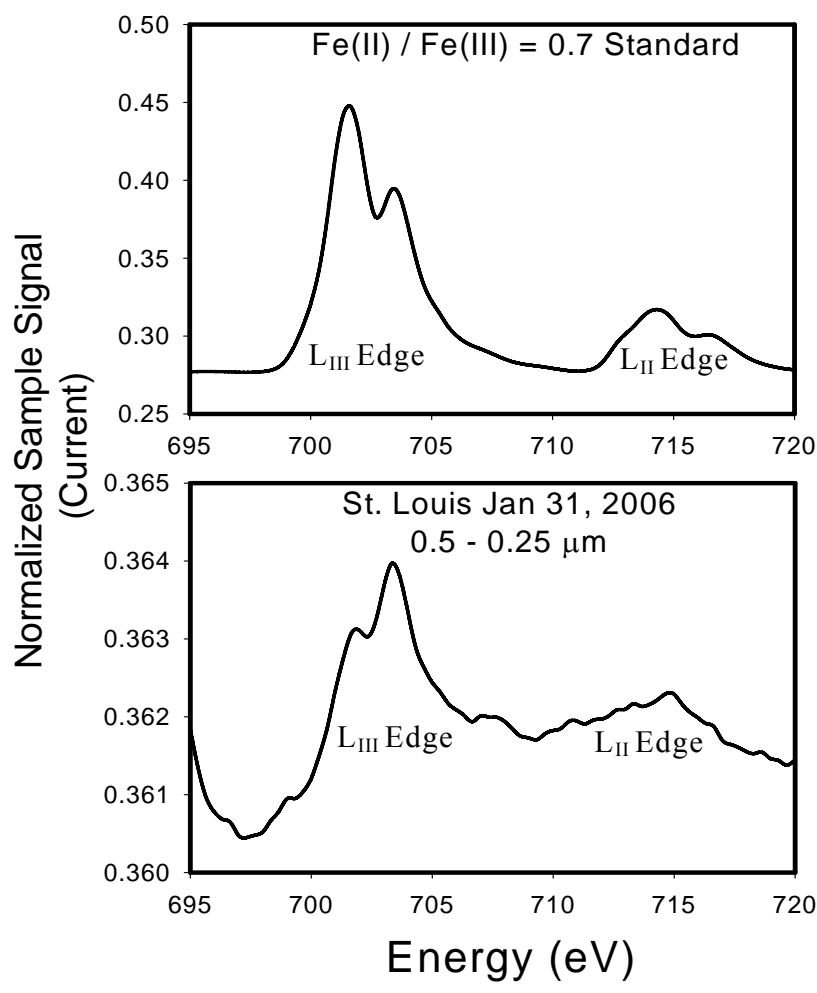

Fig. 1. Sample XANES spectra for a standard $[70 \% \mathrm{Fe}(\mathrm{II}) / 30 \%$ $\mathrm{Fe}(\mathrm{III})]$ and an ambient atmospheric sample. Note that the $\mathrm{L}_{\mathrm{II}}$ portion of the sample spectrum is relatively flat and buried in noise.

products such as silver pastes can be used to increase conductivity. However, use of Teflon substrates is problematic in that the fluorine in the material has a very strong K-edge absorption at around $697 \mathrm{eV}$. The extreme intensity of this edge causes a strong interference with the iron L-edge at around $707 \mathrm{eV}$ and, therefore, cannot be used in this measurement. Quartz is another substrate which is commonly used in atmospheric samplers, however, the lack of a smooth surface precludes its use in iron L-edge measurements. High purity aluminum foil possesses all of the required substrate attributes to be used in TEY XANES spectroscopy analysis. Therefore, a Sioutas personal cascade impactor sampler (Singh et al., 2002) was used with high-purity $(99.9995 \%)$ aluminum foil as impactor substrates for all XANES spectroscopy analyses.

At the $\mathrm{L}_{\text {III }}$ edge, divalent iron shows a sharp absorption at $707.8 \mathrm{eV}$ followed by a less intense peak at $710.5 \mathrm{eV}$, while trivalent iron shows a less intense peak around 708.0 $\mathrm{eV}$ followed by a very intense peak at $709.5 \mathrm{eV}$ (van Aken et al., 1998). Several methods have been used to calculate the $\mathrm{Fe}(\mathrm{II}) / \mathrm{Fe}$ (III) ratio from an unknown XANES spectrum (Garvie and Buseck, 1998; van Aken and Liebscher, 2002; van Aken et al., 1998). In general, these methods include calculations based on both the $\mathrm{L}_{\mathrm{II}}$ and the $\mathrm{L}_{\mathrm{III}}$ regions on the spectra. As can be seen in Fig. 1 (example spectra show-

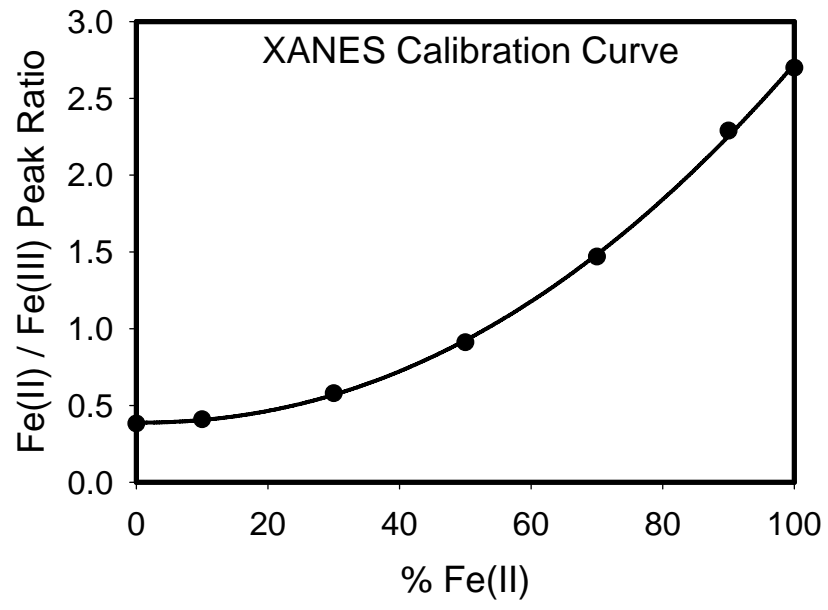

Fig. 2. The relative peak heights for the Fe(II) and Fe(III) peaks on the $\mathrm{L}_{\mathrm{III}}$ edge for varying $\mathrm{Fe}$ (II) content were prepared and analyzed by XANES spectroscopy as a function of Fe(II) fraction. The curve fit shown is a 2 nd power polynomial.

ing a $70 \% \mathrm{Fe}(\mathrm{II}) / 30 \% \mathrm{Fe}(\mathrm{III})$ standard and an actual ambient sample) the $\mathrm{L}_{\mathrm{II}}$ edge in our samples is generally not observed, or is very noisy due to the relatively low iron concentration in our samples compared to the iron standards and unknown samples used by other researchers. Therefore, a method to calculate $\mathrm{Fe}(\mathrm{II}) / \mathrm{Fe}(\mathrm{III})$ in dilute $\mathrm{Fe}$ samples was devised using only the $\mathrm{L}_{\mathrm{III}}$ edge as a reference. As the apparent peak energy fluctuate due to temperature changes and the accuracy of the monochromator, we often observed variations in the energy at which the $\mathrm{Fe}$ (II) and $\mathrm{Fe}$ (III) peaks appear. Therefore, the sample energies were normalized to known values in frequently run mixed $\mathrm{Fe}(\mathrm{II})$ and $\mathrm{Fe}(\mathrm{III})$ standards. In general, this required an energy shift of the raw spectra of about $6 \mathrm{eV}$. Next, the $\mathrm{L}_{\mathrm{III}}$ edge (or "white - line") portion of the mesh-normalized spectrum was first baseline-subtracted, then the relative $\mathrm{Fe}$ (II) and $\mathrm{Fe}(\mathrm{III})$ peak heights were determined individually and the ratio of the peak heights was found to depend on the $\mathrm{Fe}(\mathrm{II}) / \mathrm{Fe}(\mathrm{III})$ ratio. Raw, unmodified XANES spectra can be found in the supplementary material (http://www.atmos-chem-phys.net/7/2475/ 2007/acp-7-2475-2007-supplement.pdf). At low values of $\mathrm{Fe}(0)$ (which can be detected by XANES), XANES spectroscopy can be used in conjunction with a method which can measure total iron (such as ICPMS) to estimate the absolute mass of $\mathrm{Fe}$ (II) and $\mathrm{Fe}(\mathrm{III})$.

$\mathrm{Fe}(\mathrm{II})$ and $\mathrm{Fe}(\mathrm{III})$ standards were prepared from $\mathrm{Fe}(\mathrm{II})$ and $\mathrm{Fe}$ (III) ammonium sulfate salts in various proportions. A standard curve was prepared using $\mathrm{Fe}(\mathrm{II}) / \mathrm{Fe}$ (III) ratios of 0 , 0.1, 0.3, 0.5, 0.7, 0.9, and 1 (Fig. 2). Figure 2 shows that the calibration curve is best described as a 2 nd power polynomial $\left(r^{2}=1.000\right)$. Due to the shallow slope of the calibration curve below $20 \% \mathrm{Fe}(\mathrm{II})$, there is a potential for greater uncertainty in $\mathrm{Fe}$ (II) estimates where $\mathrm{Fe}$ (II) $<20 \%$. Replicate standards 
of $20 \% \mathrm{Fe}$ (II) and $50 \% \mathrm{Fe}$ (II) were analyzed to quantify the extent of this uncertainty. We found that the relative standard deviation (RSD) for the $20 \% \mathrm{Fe}$ (II) sample was 3.3\% (n=4) while the RSD for the $50 \% \mathrm{Fe}$ (II) sample was $2.0 \%(n=5)$, a $65 \%$ relative decrease in uncertainty. It should be noted, however, that the uncertainty due to sampling (RSD $>12 \%$ ) is far greater than the analytical uncertainty of this measurement.

External precision for the XANES spectroscopy measurement on actual samples was estimated by measuring the $0.5-$ $0.25 \mu \mathrm{m}$ size fraction at the 40 day time point collected on 13 February 2006 from Los Angeles. This sample was measured at five different spots on the PCIS sample line. The overall uncertainty in the reported $\mathrm{Fe}(\mathrm{II})$ values is driven by the uncertainty in XANES determined iron oxidation state ratios (uncertainty associated with the ICP-MS measurements of total iron are significantly lower). The $\mathrm{Fe}(\mathrm{II})$ concentration was found to be $24 \pm 3 \%$, which equates to a RSD of $12.5 \%$, a value which we consider to be a reasonable estimate of the uncertainty associated with the XANES measurement. For each of these trials, total $\mathrm{Fe}$ (II) was determined by multiplying the fraction of $\mathrm{Fe}$ (II) by the total iron content (from ICPMS). For this sampling day, we found an average of $5.94 \pm 0.84 \mathrm{ng} \mathrm{m}^{-3}(n=5)$, where the uncertainty is the standard deviation of all of the trials. This corresponds to a RSD of $14.2 \%$, which takes into account the uncertainty from the XANES measurement and the ICPMS measurement. It is this uncertainty estimate that was applied to all $\mathrm{Fe}(\mathrm{II})$ concentration values.

\subsection{Soluble $\mathrm{Fe}(\mathrm{II})$ and $\mathrm{Fe}(\mathrm{III})$ determination}

Soluble $\mathrm{Fe}(\mathrm{II})$ and $\mathrm{Fe}(\mathrm{III})$ was quantified using the Ferrozine (FZ) method as applied to atmospheric aerosols (Majestic et al., 2006). In short, Teflon filters were leached in $\mathrm{pH}=4.3$ acetate buffer $(500 \mu \mathrm{M}$ total acetate) under gentle agitation for two hours. After this extraction period, the leachate was immediately filtered through an acid-cleaned $0.2 \mu \mathrm{m}$ polypropylene filter (Whatman) where stock Ferrozine solution was added to the filtrate up to a final concentration of $55 \mu \mathrm{M}$ Ferrozine. About $1.5 \mathrm{~mL}$ of this solution was then pumped into a $1 \mathrm{~m}$ path-length liquid waveguide capillary cell (World Precision Instruments Inc., Sarasota, FL) and the absorption spectrum was obtained from 400 to $700 \mathrm{~nm}$. The peak at $562 \mathrm{~nm}$ (the maximum absorption of the $\mathrm{Fe}(\mathrm{II})$ FZ complex) was monitored and compared against previously made calibration curves in order to determine the labile Fe(II) content on the filter. To the remaining filtrate, hydroxylamine hydrochloride was added (final concentration $=55 \mu \mathrm{M})$ in order to reduce any $\mathrm{Fe}(\mathrm{III})$ in solution to $\mathrm{Fe}(\mathrm{II})$. Then, FZ solution was again added and the total soluble iron was measured. Soluble Fe(III) was determined by subtracting the soluble $\mathrm{Fe}$ (II) from the total soluble iron. In a previous study, we found the uncertainty associated with this measurement (including sampling and analysis uncer-

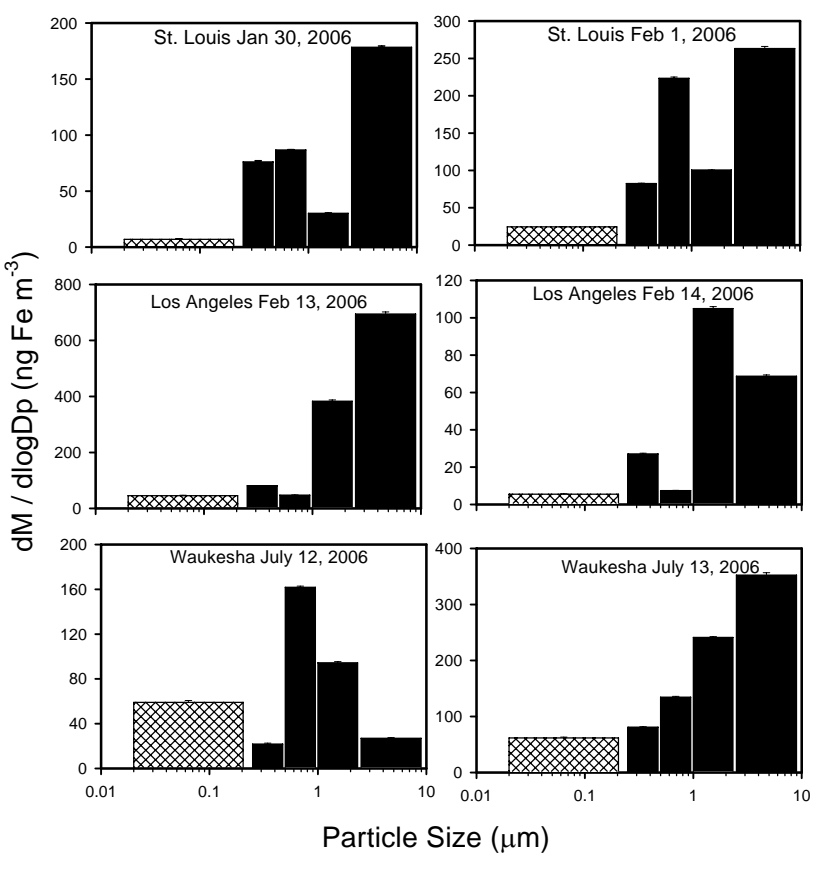

Fig. 3. Size-resolved total iron concentrations in four samples collected in East St. Louis, Los Angeles, and Waukesha, WI as measured by inductively coupled plasma - mass spectroscopy (ICPMS). The hatched portion indicates that this size fraction was only speciated by the wet-chemical method, and not by XANES spectroscopy.

tainty) to be $7.1 \%$ (Majestic et al., 2006). This propagated uncertainty was globally applied to all soluble Fe(II) data as this metric exhibited only minor variation with concentration. The detection limit of this technique was found to be $<0.1 \mu \mathrm{g} \mathrm{L}^{-1}$ which equates to $0.08 \mathrm{ng} \mathrm{Fe}$ (II) $\mathrm{m}^{-3}$ air when sampling for $24 \mathrm{~h}$ at 91 per min. Unexposed filters submitted to the same aging procedure resulted in average soluble $\mathrm{Fe}$ (II) levels of $2.2 \mathrm{ng} \mathrm{Fe}$ (II) filter ${ }^{-1}$ (ranging from below the detection limit up to $4 \mathrm{ng} \mathrm{Fe}$ (II) filter ${ }^{-1}$ ), with no dependence on the aging time, suggesting that iron was not being deposited on the filter over the course of the aging.

\section{Results}

\subsection{Aerosol sourcing}

The size-resolved iron concentrations as measured by ICPMS for the East St. Louis, Los Angeles, and Waukesha, WI sites are presented in Fig. 3. East St. Louis and Los Angeles show modes in the coarse fraction signifying resuspended soil, automobile brake dust, and road dust as a source as well as smaller modes in the sub-micron mode indicating combustion source contributions. The 12 July date in Waukesha, WI shows very little contribution in the coarse fraction, and therefore we expect very little contribution from crustal elements (aluminum, magnesium, calcium) in these samples. 


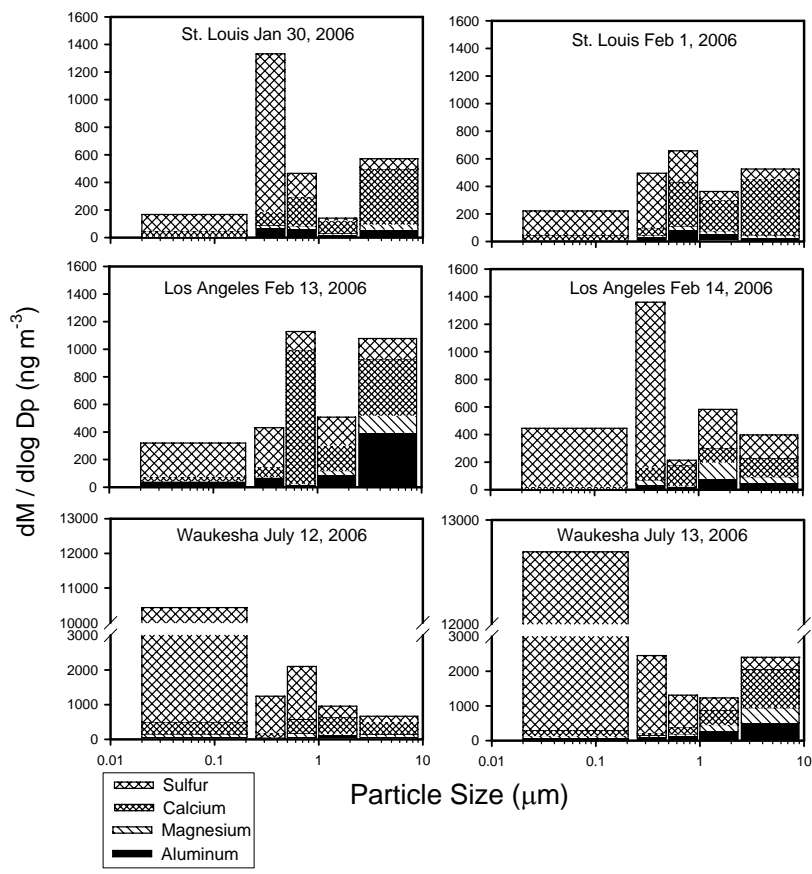

Fig. 4. Size-resolved plots of crustal elements and sulfur for the Los Angeles, East St. Louis, and Waukesha, WI samples.

For the 13 July date in Waukesha, we observe most of the iron occurring in the coarse fraction of particles, but there is no mode in the submicron fraction as in East St. Louis and Los Angeles. The solid bars in these graphs indicate that speciation [determination of both $\mathrm{Fe}$ (II) and $\mathrm{Fe}(\mathrm{III})$ ] in these size fractions were measured by both XANES spectroscopy (coupled with ICPMS measurements) and the Ferrozine method while the hatched bars (smallest size fraction) indicate speciation by only the Ferrozine method.

In order to better understand the sources of the aerosols (and iron), size-resolved plots of sulfur with common crustal elements (aluminum, calcium, and magnesium) and other source indicators (manganese, chromium, lead, barium, and copper) are shown in Figs. 4 and 5, respectively. On 12 July 2006 in Waukesha and on 14 February 2006 in Los Angeles, a smaller portion of the crustal elements (Fig. 4) are present in the coarse fraction, which is consistent with the total iron data shown in Fig. 3. In Waukesha, WI on 13 July, we observe about a 5 times increase in crustal contribution relative to 12 July in the coarse fraction, which is also consistent with the total iron size-distribution shown in Fig. 3.

The particulate matter collected in Los Angeles on 14 February 2006 shows very low air concentrations of industrial source indicator metals (Fig. 5) indicating that contribution from anthropogenic sources such as chrome plating and steel manufacturing (manganese and chromium) are small compared to the other sites. The Los Angeles PM shows a higher relative contribution from barium and copper which implies a significant contribution from mobile sources (Garg
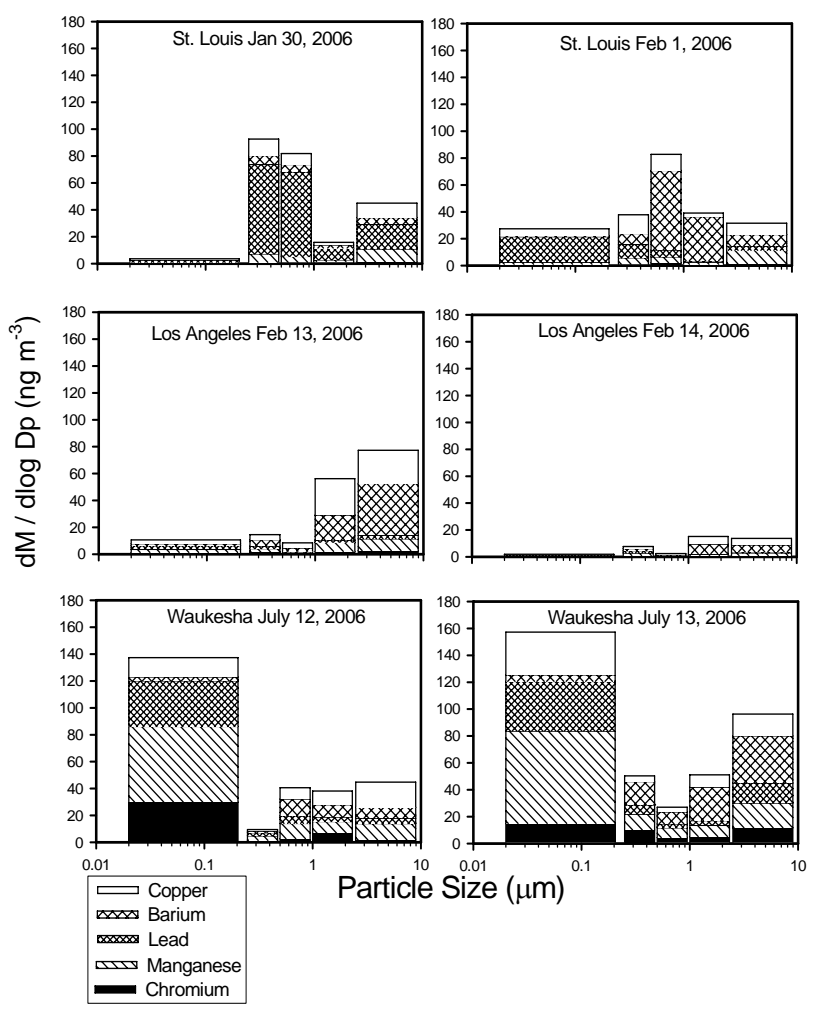

Fig. 5. Size-resolved plots of other metals as source indicators for the Los Angeles, East St. Louis, and Waukesha, WI samples.

et al., 2000). The East St. Louis PM shows a very high relative contribution from lead on 30 January 2006 and from both lead and barium on 1 February 2006. To a lesser extent, copper and manganese are also significant in the 1 February 2006 aerosols. Overall, the Waukesha, WI sampling site shows the greatest amount of industrial source indicator metals with a consistent relative metals distribution over the course of the two days. These values are about 2 times those in East St. Louis and about 10 times those in Los Angeles. Los Angeles is impacted by mobile sources much more so than the other two sites and the much lower metal levels in Los Angeles demonstrate the impact of industrial sources on concentration of metals associated with particulate matter. Relative to the other two sites, the particulate matter collected in Waukesha showed extremely high levels of chromium and manganese, especially in the ultra-fine fraction. At the East St. Louis and Waukesha sampling sites, a significantly greater fraction of copper (45-60\%) is found in the submicron fraction in comparison with mobile-source dominated Los Angeles site $(<20 \%)$. Therefore, at these two sites, there is another source contributing significant levels of copper excess of that from motor vehicles. Likely sources in Waukesha are a casting foundry less than $1.5 \mathrm{~km}$ directly east of the sampling site and a stainless steel fabrication facility approximately $0.3 \mathrm{~km}$ south of the site. A significant amount of lead is also observed in the ultra-fine fraction. 


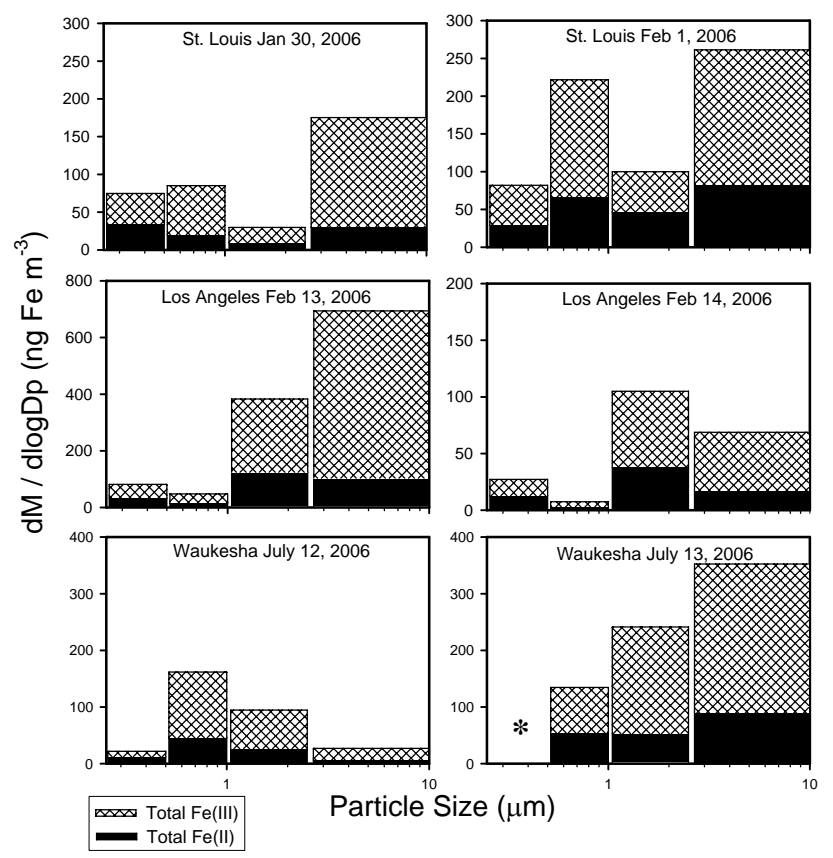

Fig. 6. Initial size-resolved total Fe(II) (solid) and Fe(III) (hatched) concentrations in PM10 samples collected in East St. Louis and Los Angeles. $\mathrm{Fe}(\mathrm{II}) / \mathrm{Fe}$ (III) ratios were measured by x-ray absorption near edge structure (XANES) spectroscopy.

\subsection{XANES speciation}

In Fig. 6, we show the total size-resolved Fe(II) (solid fraction) and total $\mathrm{Fe}(\mathrm{III})$ (hatched fraction) as measured by XANES spectroscopy and ICPMS. Note that there is no data for the size fraction $<0.25 \mu \mathrm{m}$ as it is not possible to use the necessary aluminum substrate as the after-filter in the PCIS. The dominance of $\mathrm{Fe}(\mathrm{III})$ in all size fractions and samples is clearly evident. Our experiments were not able to determine in which chemical form the Fe(III) is bound, but it is likely found as goethite, hematite, or magnetite (Hoffmann et al., 1996). The “*” in the 13 July 2006 Waukesha sizedistribution indicates that no XANES data was available for this size-fraction on this day.

Figure 7 presents the size-resolved total Fe(II) and Fe(III) content (derived from XANES and ICPMS measurements) after aging the 30 January 2006 sample collected at the St. Louis Midwest Supersite over the course of 40 days in the BioTron. In this sample, a sharp increase (100\% increase) in $\mathrm{Fe}$ (II) is observed in the coarse fraction between zero and ten days. Following 10 days, however, there is very little change in the $\mathrm{Fe}(\mathrm{II}) / \mathrm{Fe}$ (III) ratio in this size fraction. In contrast, the smallest size fraction measured $(0.5-0.25 \mu \mathrm{m})$ shows a relatively small increase (17\%) in the Fe(II) fraction after 10 days, and then decreases significantly over the next 30 days of aging.

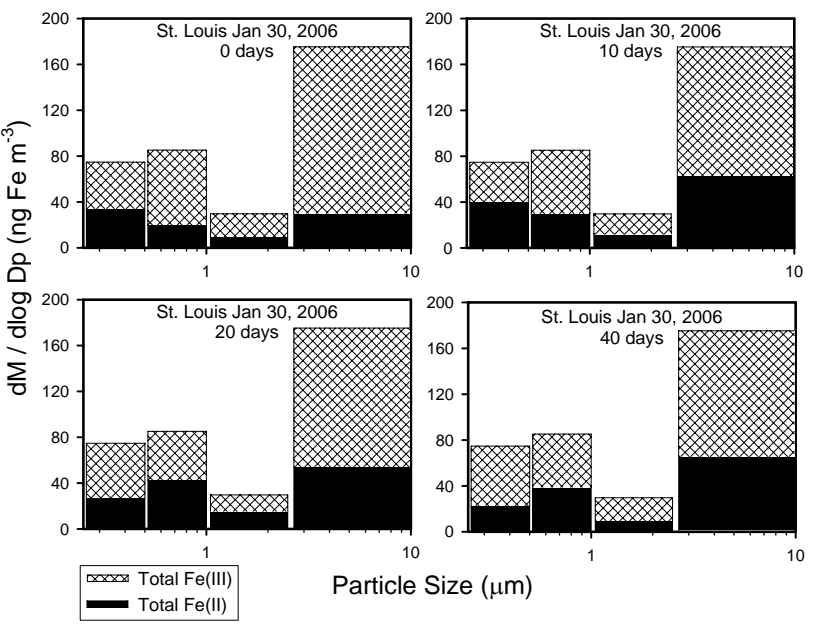

Fig. 7. Total Fe(II) (solid) and Fe(III) (hatched) size-resolved concentrations (measured by XANES) for the 30 January 2006 sample from East St. Louis. This series of graphs shows how each size fraction changes over the course of the 40 day aging period.

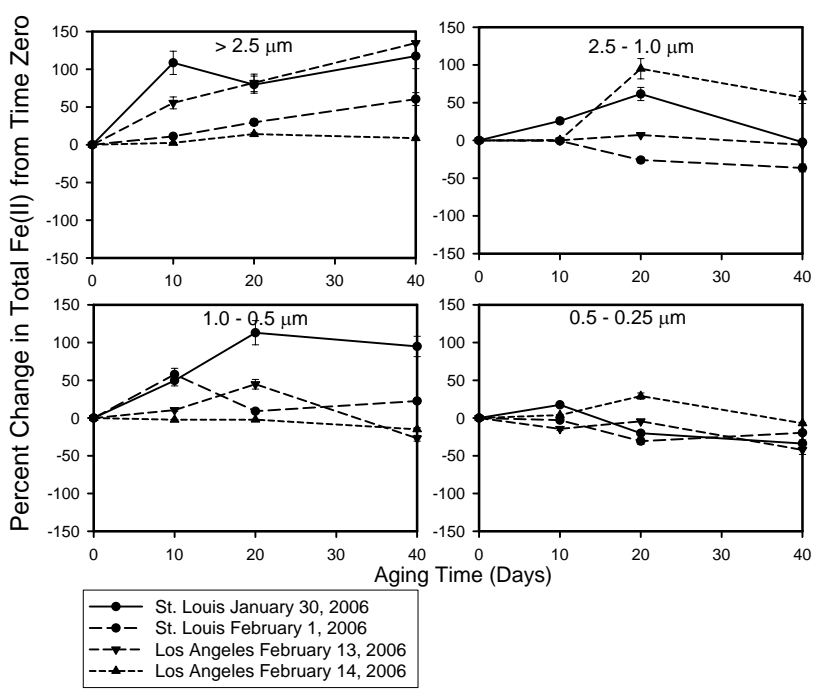

Fig. 8. Percent change of total Fe(II) (from time=0) for the four East St. Louis and Los Angeles samples aged over 40 days as measured by XANES.

The plots in Fig. 8 summarize the percent change in Fe(II) for all of the samples collected in St. Louis and Los Angeles. Analogous plots (in $\mathrm{ng} \mathrm{Fe}(\mathrm{II}) \mathrm{m}^{-3}$ ) can be found in the supplementary material (http://www.atmos-chem-phys.net/ 7/2475/2007/acp-7-2475-2007-supplement.pdf). As each plot shows a different size-fraction, the trends for Fe(II) collected in varying sizes can be monitored over the course of the aging period. In general, the $\mathrm{Fe}$ (II) contained in the coarse fraction $(>2.5 \mu \mathrm{m})$ tends to increase over time while, in the smallest fraction measured $(0.5-0.25 \mu \mathrm{m})$, the $\mathrm{Fe}(\mathrm{II})$ shows a tendency to decrease over this time period. The 


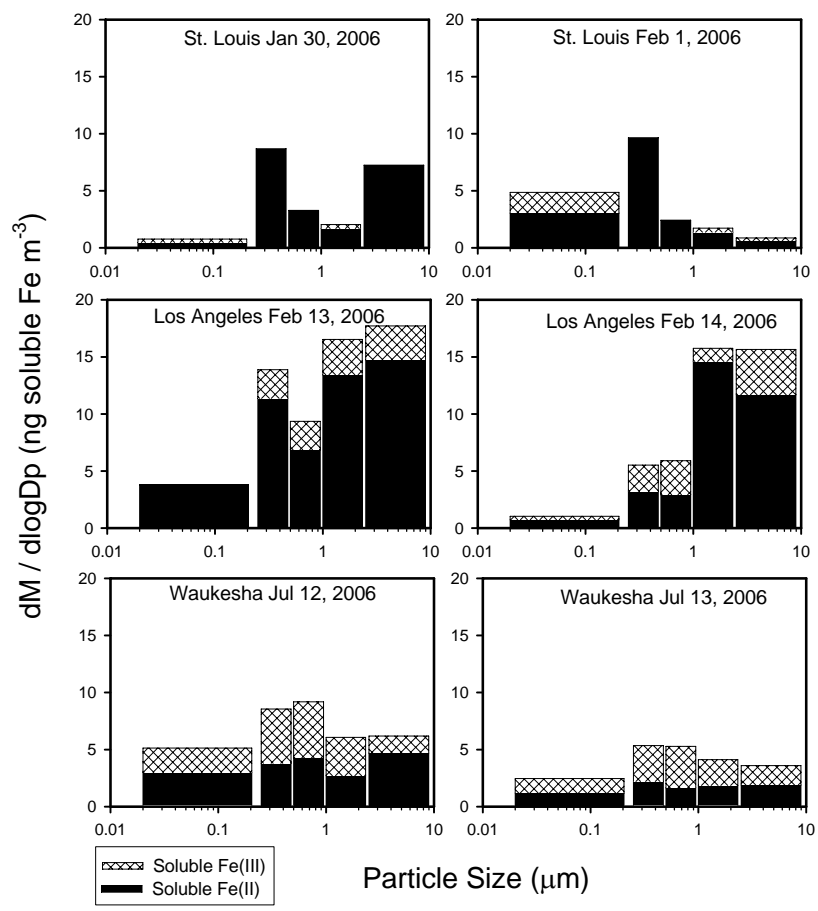

Fig. 9. Initial size-resolved soluble $\mathrm{Fe}(\mathrm{II})$ (solid) and $\mathrm{Fe}(\mathrm{III})$ (hatched) concentrations in PM10 samples collected in East St. Louis, Los Angeles, and Waukesha, WI. Soluble Fe(II) and $\mathrm{Fe}(\mathrm{III})$ were measured using the Ferrozine method followed by addition of hydroxylamine hydrochloride.

intermediate size fractions show very little change over the course of the study. As most of the iron tends to be concentrated in the coarse fraction $(>2.5 \mu \mathrm{m})$, this leads to an overall tendency towards Fe(II) in these atmospheric particles.

\subsection{Soluble iron speciation}

The size-fractioned soluble Fe(II) (solid portion) and Fe(III) (hatched portion) content in the unaged ( $t=0$ days) samples are presented in Fig. 9. Despite the total iron levels in a sample, all of the soluble iron levels [Fe(II)+Fe(III)] range from around 0.4 to $11 \mathrm{ng} \mathrm{m}^{-3}$. Unlike the relatively low $\mathrm{Fe}(\mathrm{II}) / \mathrm{Fe}$ (III) ratios observed in the bulk particles, the soluble fraction tends to be primarily $\mathrm{Fe}(\mathrm{II})$, although significant amounts of $\mathrm{Fe}$ (III) are still present in many samples. It is also observed that each sampling site has a different soluble iron signature for these two sampling days. The PM from Waukesha, WI shows a relatively even iron sizedistribution with a very small mode around $1 \mu \mathrm{m}$. Further, for all size fractions on both days sampled in Waukesha, soluble $\mathrm{Fe}$ (II) and soluble $\mathrm{Fe}$ (III) were approximately equal (i.e. $\left.\mathrm{Fe}(\mathrm{II})_{\mathrm{sol}} / \mathrm{Fe}(\text { total })_{\text {sol }} \sim 0.5\right)$. The PM collected in Los Angeles showed a soluble iron size distribution more similar to that of the total iron distribution from Fig. 3 prior to aging, and the greatest air concentration of soluble iron of any of the sites. The Los Angeles site also shows a much greater relative coarse contribution of soluble iron compared with the other two sites. In general, the $\mathrm{Fe}(\mathrm{II})_{\mathrm{sol}} / \mathrm{Fe}(\text { total })_{\text {sol }}$ fractions in Los Angeles were around 0.75, with the ratio approaching 0.9 for the particles $<0.25 \mu \mathrm{m}$, significantly greater than the Waukesha, WI site. Lastly, both East St. Louis samples showed modes at around $0.5 \mu \mathrm{m}$, but little other similarities were present. The 1 February 2006 day showed, by far, the greatest difference between coarse and PM2.5 soluble iron for all samples with the PM2.5 fraction about 32 times greater than the coarse fraction. In contrast to the PM collected in Los Angeles, the PM collected in East St. Louis showed a relatively low $\mathrm{Fe}(\mathrm{II})_{\mathrm{sol}} / \mathrm{Fe}$ (total $)_{\text {sol }}$ ratio of 0.4 for the particles $<0.25 \mu \mathrm{m}$ and an extremely high ratio $(0.98)$ for all other size fractions indicating that very little soluble $\mathrm{Fe}$ (III) is present in the $\mathrm{PM}>0.25 \mu \mathrm{m}$ collected in East St. Louis during this sampling period.

A summary and comparison of percent leachable iron in the coarse and PM2.5 fractions measured at East St. Louis, Los Angeles, and Waukesha is presented in Table 1. Table 1 shows that the fraction of labile iron can significantly vary depending on the sample as the total soluble iron fraction ranged from $<1-23 \%$ of the total iron. This likely depends on the atmospheric processing of the aerosol prior to collection as well as the source. Further, with the exception of the 14 February 2006 Los Angeles and the 12 July 2006 Waukesha, WI sampling dates, the PM2.5 aerosols have a greater labile fraction than the coarse particles. Prior to both of these sampling days, there was a light rain and, as a result, the coarse particles were largely washed out of the atmosphere. This resulted in relatively low concentrations of coarse iron as well as different iron speciation relative to the other sampling days (see Table 1).

Table 1 also presents a comparison of leachable Fe(II) to total $\mathrm{Fe}$ (II). Of the total $\mathrm{Fe}$ (II), the leachable fraction of PM2.5 Fe(II) ranges from 9\% up to almost $40 \%$. While this is a relatively broad range, it is clear that a majority of the $\mathrm{Fe}$ (II) in these urban atmospheric aerosols are not in a soluble phase. Size-fraction comparisons in Table 1 show that three of the samples have a greater labile fraction in the coarse particles while the other two show a greater labile fraction in the PM2.5 fraction. This comparison was not possible on the 13 July 2006 sample collected in Waukesha, WI as XANES data was not available. It should be noted, however, that this is not a direct comparison as particles $<0.25 \mu \mathrm{m}$ are not included in this analysis because XANES analysis was not possible for this size-fraction. Given that a majority of the soluble iron in the particles $<0.25 \mu \mathrm{m}$ is $\mathrm{Fe}$ (II), the actual fraction of soluble $\mathrm{Fe}$ (II) of the total $\mathrm{Fe}$ (II) in the PM2.5 size range will be greater than shown in Table 1. This effect will be marginal, however, as the iron concentration in this fraction is generally small relative to the other size fractions.

The influence of aging on size-resolved iron is shown in Fig. 10 for the samples collected on 12 July 2006 from 
Table 1. Comparison of total leachable iron to Total Iron and Total Fe(II) with no aging.

\begin{tabular}{lccccc}
\hline Sampling Day & Size Fraction & $\begin{array}{c}\text { Total Iron } \\
\left(\mathrm{ng} \mathrm{m}^{-3}\right)\end{array}$ & $\begin{array}{c}\text { \% Leachable Fe(II) } \\
\text { of Total Iron }\end{array}$ & $\begin{array}{c}\text { \% Leachable Fe(II) } \\
\text { of Total Fe(II)** }\end{array}$ & $\begin{array}{c}\text { \% Leachable Fe } \\
\text { of Total Iron }\end{array}$ \\
\hline St. Louis, 30 Jan 2006 & $>2.5 \mu \mathrm{m}$ & 107.4 & 4.1 & 24.0 & 4.1 \\
St. Louis, 30 Jan 2006 & PM 2.5 & 68.6 & 7.1 & 21.3 & 7.8 \\
St. Louis, 1 Feb 2006 & $>2.5 \mu \mathrm{m}$ & 158.5 & 0.23 & 0.7 & 0.33 \\
St. Louis, 1 Feb 2006 & PM 2.5 & 158.9 & 4.8 & 8.8 & 6.1 \\
Los Angeles, 13 Feb 2006 & $>2.5 \mu \mathrm{m}$ & 417.8 & 2.1 & 14.3 & 2.6 \\
Los Angeles, 13 Feb 2006 & PM 2.5 & 241.0 & 6.2 & 4.9 & 2.4 \\
Los Angeles, 14 Feb 2006 & $>2.5 \mu \mathrm{m}$ & 41.4 & 17.0 & 38.6 & 77.8 \\
Los Angeles, 14 Feb 2006 & PM 2.5 & 58.2 & 14.5 & 24.5 & 23.0 \\
Waukesha, 12 July 2006 & $>2.5 \mu \mathrm{m}$ & 16.2 & 17.5 & 2.1 & 8.5 \\
Waukesha, 12 July 2006 & PM 2.5 & 157.6 & 4.3 & N/A & 1.0 \\
Waukesha, 13 July 2006 & $>2.5 \mu \mathrm{m}$ & 212.2 & 0.54 & 1.4 & 3.3 \\
Waukesha, 13 July 2006 & PM 2.5 & 228.6 & & & \\
\hline
\end{tabular}

** XANES data is not available for particles $<0.25 \mu \mathrm{m}$. Therefore, the PM2.5 row signifies particle size range from $0.25-2.5 \mu \mathrm{m}$ for this column only.

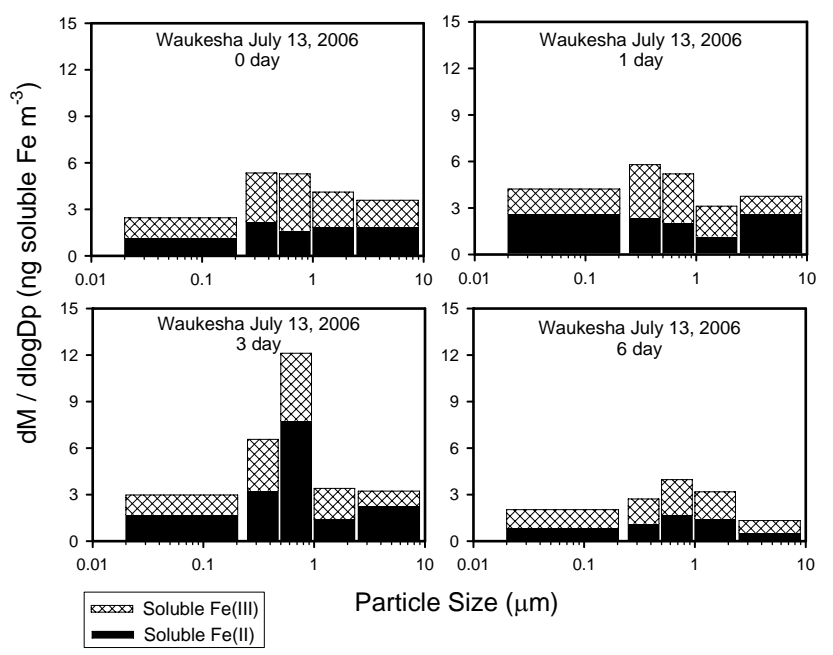

Fig. 10. Soluble Fe(II) (solid) and Fe(III) (hatched) size-resolved concentrations (measured by the Ferrozine method) for the 13 July 2006 sample from Waukesha, WI. This series of graphs shows how each size fraction changes over the course of the 10 day aging period.

Waukesha, WI. Over the six day aging period, the soluble $\mathrm{Fe}(\mathrm{II})$ in the coarse fraction is seen to slightly increase over the first day, then decreases over 3-6 days whereas the soluble $\mathrm{Fe}$ (III) content in the coarse fraction remains relatively steady. This leads to an overall decrease in soluble iron in the coarse fraction after three days of aging. The most prominent feature in these plots is the Fe(II) spike at 3 days in the size range of $1-0.25 \mu \mathrm{m}$ and the $\mathrm{Fe}(\mathrm{II})$ spike at 1 day for particles $<0.25 \mu \mathrm{m}$, while $\mathrm{Fe}(\mathrm{III})$ remains relatively constant. This indicates that $\mathrm{Fe}$ (II) and/or Fe(III) are undergoing chemical changes which result in a higher solubility for $\mathrm{Fe}(\mathrm{II})$. After six days, however, both species return to their approximate initial levels, suggesting that insoluble iron forms of $\mathrm{Fe}$ (II) and $\mathrm{Fe}(\mathrm{III})$ are being formed.

The particulate matter collected at the East St. Louis and Los Angeles sites were aged for 40 days and the Waukesha samples were aged for 10 days. The results of the East St. Louis and Los Angeles study are shown in Fig. 11 and the results of the Waukesha study is shown in Fig. 12. Both figures present the percent change (from time $=0$ ) of soluble $\mathrm{Fe}(\mathrm{II})$ versus aging time. Analogous plots (in $\mathrm{ng} \mathrm{Fe}(\mathrm{II}) \mathrm{m}^{-3}$ ) can be found in the supplementary material (http://www.atmos-chem-phys.net/7/2475/ 2007/acp-7-2475-2007-supplement.pdf).

In the 40 day experiments, four data points $(0,10,20$, and 40 days) were collected (Fig. 11). For three of the four sampling days in St. Louis and Los Angeles, a sharp decrease of soluble Fe(II) within 10 days of sampling is observed. The 1 February 2006 sampling date in East St. Louis is the only one which does not follow this trend. In this day, both size fractions $>1 \mu \mathrm{m}$ actually show an increase in $\mathrm{Fe}(\mathrm{II})$ after the initial measurement. The iron contained in the sub-micron particles follow the trend of the other sampling days. This reason for this difference is not yet clear, but likely is, in part, due to the very different initial soluble Fe(II) compared to the other days as seen in Fig. 9.

In order to achieve a better understanding of the chemical processes which occur within 10 days of PM collection, the aerosols from Waukesha, WI were aged for shorter time periods of $0,1,3,6$, and 10 days. The air concentration of the soluble Fe(II) is presented in Fig. 12 for all of these time points. These plots show that in the sub-micron region, soluble Fe(II) shows a sharp spike at all size-fractions around 1-3 days. Following this spike, the values return to near their initial state. The super-micron particles did not show this behavior. In fact, these particles show very little, if any, increase in soluble Fe(II) over the course of the study, and generally showed a decreasing trend. These results are also 


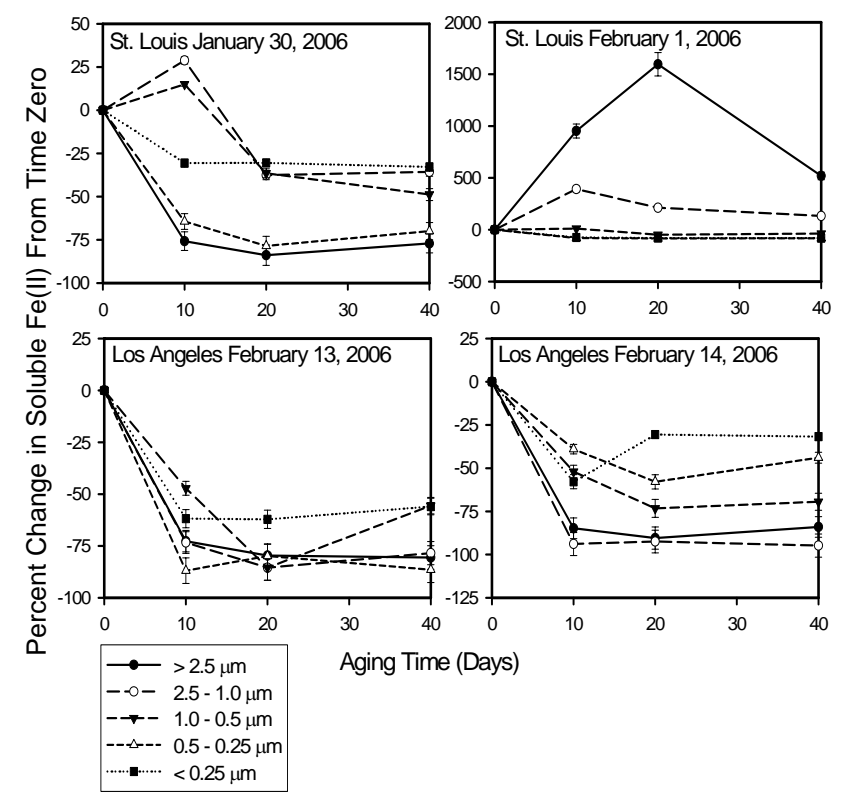

Fig. 11. Percent change from time $=0$ of soluble $\mathrm{Fe}(\mathrm{II})$ for all St. Louis and Los Angeles samples aged over 40 days as measured by the Ferrozine method.

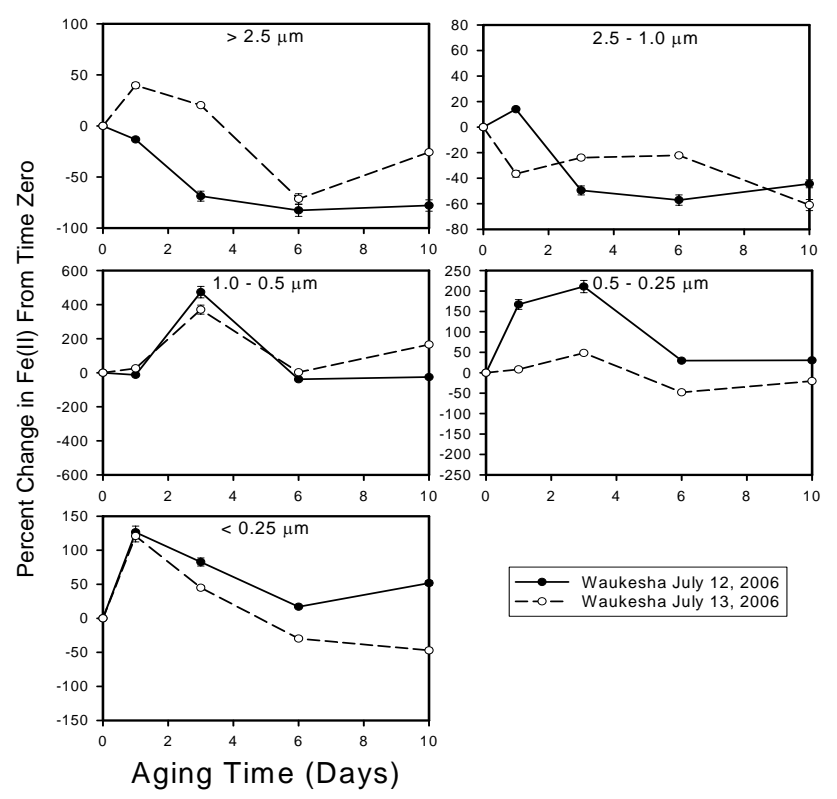

Fig. 12. Percent change from time $=0$ of soluble Fe(II) air concentrations for all Waukesha, WI samples aged over 10 days as measured by the Ferrozine method.

summarized in Table 2.

\section{Discussion}

In this study, we have developed a XANES spectroscopy method to determine the total $\mathrm{Fe}$ (II) and $\mathrm{Fe}$ (III) content in atmospheric aerosol personal exposure samples. When applied in parallel with ICPMS, XANES spectroscopy can establish the average iron oxidation state in an aerosol sample. Coupled with a wet-chemical iron speciation method, we measured how the speciation of ambient iron changes under tightly controlled atmospheric conditions. In all sampling locations, we found that the total iron in all size fractions $>0.25 \mu \mathrm{m}$ is primarily in the form of $\mathrm{Fe}(\mathrm{III})$, however most of the soluble fraction is in the form of $\mathrm{Fe}(\mathrm{II})$ with variable but significant contributions of $\mathrm{Fe}(\mathrm{III})$. It was also found that a majority of the $\mathrm{Fe}(\mathrm{II})$ in the PM2.5 fraction was not labile in our leaching solution ( $\mathrm{pH}=4.3$ acetate buffer).

Because the PM is collected in a narrow band, it is possible that some of the PM (especially the PM closest to the collection substrate) was not able to fully interact with the radiation or the atmosphere during the aging process. By knowing the total mass of the particles, assuming the average density of the particles to be $0.8 \mathrm{~g} \mathrm{ml}^{-1}$, and calculating the deposition area to be $30 \mathrm{~mm}^{2}$, we can estimate the number of particle layers formed after sample collection. For this calculation, it was also assumed that the particles were packed in distinct layers. For the $>2.5 \mu \mathrm{m}, 2.5-1.0 \mu \mathrm{m}$, and the 1.0 $0.5 \mu \mathrm{m}$ size fractions, we found that the PM forms an average of $1.0 \pm 0.6$ layers. The smallest size fraction $(0.5-0.25 \mu \mathrm{m})$ which is collected by impaction forms an estimated $7.0 \pm 1.8$ layers. From this calculation, we can conclude that, for the three largest size fractions, the radiation and the air are likely interacting with all of the particles equally. While this may be not be the case for the $0.5-0.25$ size fraction, we do not observe the $\mathrm{Fe}(\mathrm{II})$ trends in this fraction to deviate significantly during any aging study compared to the $1.0-0.5 \mu \mathrm{m}$ or the $<0.25 \mu \mathrm{m}$ fractions (see Figs. 8, 10, 11, and 12). Therefore, we have assumed in this study that the atmosphere and radiation is interacting with all of the particles equally.

Very little similarity is observed between the total iron and the soluble iron trends. The XANES data reveals that the overall $\mathrm{Fe}$ (II) and $\mathrm{Fe}$ (III) trends follow a relatively smooth relationship with very few (and less pronounced) Fe(II) spikes observed for any size fraction. However, the soluble iron fraction (especially in the sub-micron fraction) shows distinct peaks of $\mathrm{Fe}$ (II) ranging from 1-3 days. The reason for this apparent contradiction could be due to any one or a combination of factors. First, the soluble iron is generally a very small fraction of the total iron in the sample ranging from $<1 \%$ to about $20 \%$ of the total (see Table 1). Therefore, small changes in the soluble iron fraction may be below the detection limit in the less-sensitive total iron XANES measurements. Second, even though $\mathrm{Fe}(0)$ was not observed in the XANES measurements, it is possible that a very small fraction $(<1 \%)$ of the total iron was, in fact, $\mathrm{Fe}(0)$. Ultrafine $\mathrm{Fe}(0)$ particles have been observed by other researchers 
Table 2. Time (in days) for soluble Fe(II) to reach a maximum value in both Waukesha samples. Oxidation times are the time it takes for the soluble iron values to come back to equilibrium (from time $t=0$ ). Note that Fe(II) peaks are observed only in the sub-micron fractions.

\begin{tabular}{ccc}
\hline Size Fraction & Time to Reach Maximum Fe(II) Content & Time for Fe(II) to Oxidize \\
\hline$>2.5 \mu \mathrm{m}$ & No Significant Peak & Not Significant \\
$2.5-1.0 \mu \mathrm{m}$ & No Significant Peak & Not Significant \\
$1.0-0.5 \mu \mathrm{m}$ & 3 days & 6 days \\
$0.5-0.25 \mu \mathrm{m}$ & 3 days & 6 days \\
$<0.25 \mu \mathrm{m}$ & 1 day & 6 days \\
\hline
\end{tabular}

to oxidize to $\mathrm{Fe}$ (II) and then $\mathrm{Fe}$ (III) (Papaefthymiou et al., 1990; Parkhomenko et al., 1990), which would also explain the behavior of the submicron soluble iron fraction in the Waukesha, WI samples during short-term transport.

The largest discrepancy between the XANES and soluble iron data is observed on the 13 February 2006 sampling day in Los Angeles. Figures 8 and 11 show that total Fe(II) in the coarse fraction increases at a significant rate while the soluble fraction of $\mathrm{Fe}(\mathrm{II})$ sharply decreases prior to 10 days of aging. This implies that, overall, $\mathrm{Fe}(\mathrm{II})$ is being formed, however the specific form of $\mathrm{Fe}$ (II) is not soluble or addressable to our leaching solution. Studies by Zhu et al. (1992) documented that photochemical reduction of goethite $(\alpha-\mathrm{FeOOH})$ from $\mathrm{Fe}(\mathrm{III})$ to $\mathrm{Fe}$ (II) does occur, and that this reduction has no effect on the solubility of the goethite. Because this effect in this study is pronounced in the coarse particle fraction, which likely has a strong crustal component, these data indicate the strong possibility that significant amounts of goethite may be present in the coarse fraction on this sampling day.

The XANES results showed that $\mathrm{Fe}$ (II) associated with the coarse fraction had a tendency to increase over time while the $\mathrm{Fe}$ (II) associated with the smaller fraction $(0.5-0.25 \mu \mathrm{m})$ tended to slowly decrease over time. These changes were sometimes significant over a 40 day time-span, but this is much longer than the atmospheric residence time of most atmospheric PM. On the timescale of urban aerosols (around 1 week), there was generally very little change in the total $\mathrm{Fe}$ (II) concentrations. Because of the applications to long-range transport, however, a discussion regarding the potential processes which dictate species-conversion is warranted. Iron redox reactions may occur within the aerosol water layer and/or at the particle-air and particle-water interfaces. The absorption spectrum of $[\mathrm{Fe}(\mathrm{III}) \mathrm{OH}]^{2+}$ overlaps the solar spectrum, and therefore, as studies have shown, cloud processing can play an important role in the reduction of iron in atmospheric waters (Faust and Hoigne, 1990). However, at low $\mathrm{pH}$ values (similar to those found in hydrated atmospheric aerosols), $[\mathrm{Fe}(\mathrm{III}) \mathrm{OH}]^{2+}$ is not present in large amounts (Zhuang et al., 1992) and the dominant Fe(III) species at these conditions is $\left[\mathrm{Fe}(\mathrm{III})\left(\mathrm{H}_{2} \mathrm{O}\right)_{6}\right]^{3+}$. Direct photoreduction of $\left[\mathrm{Fe}(\mathrm{III})\left(\mathrm{H}_{2} \mathrm{O}\right)_{6}\right]^{3+}$ is likely only a minor mechanism as its absorption spectrum does not significantly overlap with the solar spectrum (Faust and Hoigne, 1990). Therefore, it is likely that other components of the aerosol are responsible for the reduction of $\left[\mathrm{Fe}(\mathrm{III})\left(\mathrm{H}_{2} \mathrm{O}\right)_{6}\right]^{3+}$ under environmental conditions usually associated with aerosols. It is known that iron plays an integral role in the sulfur cycle and this may lead to the oxidation and reduction of iron. A discussion of possible mechanisms is discussed in detail elsewhere (Conklin and Hoffmann, 1988; Zhuang et al., 1992). Iron is also known to interact with organic carbon in aerosols where iron red-ox changes have been observed to occur (Kieber et al., 2005; Pehkonen et al., 1993). For example, photo-reduction of Fe(III)-carboxylic acid complexes has been shown to be a major source of Fe(II) (Okada et al., 2006). Zhuang et al. (1992) and Conklin and Hoffmann (1988) discuss, in detail, potential redox mechanisms. Further oxidation of iron may occur from interaction with atmospheric oxygen, as detailed elsewhere (Valavanidis et al., 2000).

Only a few published studies have examined the red-ox transformations of PM-associated iron during atmospheric transport. Although an estimate of aerosol transport time was not given, Zhuang et al. (1992) found that significant conversion between $\mathrm{Fe}(\mathrm{II})$ and $\mathrm{Fe}(\mathrm{III})$ can occur during transport, with reduction of $\mathrm{Fe}(\mathrm{III})$ to $\mathrm{Fe}$ (II) being more significant than oxidation of $\mathrm{Fe}$ (II) to $\mathrm{Fe}(\mathrm{III})$ in marine aerosols. A number of studies have sought to measure the rates of photoreduction of $\mathrm{Fe}(\mathrm{III})$ in aqueous leaches or suspensions of aerosols (Okada et al., 2006; Zhu et al., 1993). These studies found that, in the leachate, the $\mathrm{Fe}(\mathrm{II})$ levels quickly increase upon irradiation of the aerosol solution, with the levels reaching a pseudo steady-state within $45 \mathrm{~min}$. Irradiation studies performed on atmospheric cloud water have reported similar results (Arakaki and Faust, 1998). It should be noted that, in all of these irradiation studies, the aerosols were "trapped" in a leaching solution, and therefore unavailable to atmospheric oxygen.

Because of the low relative humidity condition used in this study, any changes in iron oxidation state will likely be the result of heterogeneous surface chemistry and likely cannot be extended to those processes taking place in cloud and fog waters (Arakaki and Faust, 1998; Faust and Hoigne, 1990), which can have significant impacts in certain environments 
during atmospheric transport. However, it should be noted that even at the humidity levels used, the aerosols are not dry - a water layer is present in the aerosols in which aqueous phase chemistry can take place.

In this study, comparison to the total $\mathrm{Fe}$ (II) and Fe(III) trends reveals that more drastic changes were noted in the soluble iron fraction compared to the total. With the exception of the super-micron fraction on the 1 February sampling date, we observed that, after around 10 days of aging, the soluble fraction of $\mathrm{Fe}$ (II) was stable for at least 40 days. In the short-term time experiments, we observed a spike in soluble Fe(II) after 1-3 days, followed by a sharp decline after 6-10 days (see Table 3). The aerosols in this project were aged in an atmosphere which only represents one possible atmospheric condition. It is not clear what changes in the iron speciation would occur under different conditions (i.e., cloudy, very high or low relative humidities). However, since the changes in soluble iron occur rather rapidly (1-3 days), our experiments imply that atmospheric processing can have a large effect on the actual exposure of soluble iron.

Acknowledgements. This study was supported by the Health Effects Institute grant \#02-11. This work is based in part upon research conducted at the Synchrotron Radiation Center, University of Wisconsin-Madison, which is supported by the National Science Foundation under award no. DMR-0537588. We also wish to thank Mary Severson, Bob Pedley, and Mark Bissen of the SRC for their assistance with the XANES spectroscopy analysis.

Edited by: M. Ammann

\section{References}

Arakaki, T. and Faust, B. C.: Sources, sinks, and mechanisms of hydroxyl radical $\left(\mathrm{OH}^{\cdot}\right)$ photoproduction and consumption in authentic acidic continental cloud waters from Whiteface Mountain, New York: The role of the Fe(r) (r=II, III) photochemical cycle, J. Geophys. Res., 103(D3), 3487-3504, 1998.

Arakaki, T., Kuroki, Y., Okada, K., Nakama, Y., Ikota, H., Kinjo, M., Higuchi, T., Uehara, M., and Tanahara, A.: Chemical composition and photochemical formation of hydroxyl radicals in aqueous extracts of aerosol particles collected in Okinawa, Japan, Atmos. Environ., 40(25), 4764-4774, 2006.

Bae, M. S., Schauer, J. J., DeMinter, J. T., and Turner, J. R.: Hourly and daily patterns of particle-phase organic and elemental carbon concentrations in the urban atmosphere, J. Air Waste Manage. Assoc., 54(7), 823-833, 2004.

Conklin, M. H. and Hoffmann, M. R.: Metal-ion sulfur(IV) chemistry 3. Thermodynamics and kinetics of transient iron(III) sulfur(IV) complexes, Environ. Sci. Technol., 22(8), 899-907, 1988.

Donaldson, K., Brown, D. M., Mitchell, C., Dineva, M., Beswick, P. H., Gilmour, P., and MacNee, W.: Free radical activity of PM10: Iron-mediated generation of hydroxyl radicals, Environ. Health Perspect., 105, 1285-1289, 1997.
Faust, B. C. and Hoffmann, M. R.: Photoinduced reductive dissolution of alpha- $\mathrm{Fe}_{2} \mathrm{O}_{3}$ by bisulfite, Environ. Sci. Technol., 20(9), 943-948, 1986.

Faust, B. C. and Hoigne, J.: Photolysis of Fe(III)-hydroxy complexes as sources of $\mathrm{OH}$ radicals in clouds, fog and rain, Atmos. Environ., 24(1), 79-89, 1990.

Garg, B. D., Cadle, S. H., Mulawa, P. A., Groblicki, P. J., Laroo, C., and Parr, G. A.: Brake wear particulate matter emissions, Environ. Sci. Technol., 34(21), 4463-4469, 2000.

Garvie, L. A. J. and Buseck, P. R.: Ratios of ferrous to ferric iron from nanometre-sized areas in minerals, Nature, 396, 667-670, 1998.

Hoffmann, P., Dedik, A. N., Ensling, J., Weinbruch, S., Weber, S., Sinner, T., Gutlich, P., and Ortner, H. M.: Speciation of iron in atmospheric aerosol samples, J. Aerosol Sci., 27(2), 325-337, 1996.

Hoffmann, P., Sinne, R. T., Dedik, A. N., Karandashev, V. K., Malyshev, A. A., Weber, S., and Ortner, H. M.: Iron in atmospheric aqueous and particulate samples, Fresenius J. Anal. Chem., 350(1-2), 34-37, 1994.

Jacob, D. J., Waldman, J. M., Munger, J. W., and Hoffmann, M. R.: Chemical-composition of fogwater collected along the California coast, Environ. Sci. Technol., 19(8), 730-736, 1985.

Kieber. R. J., Skrabal. S. A., Smith. B. J., and Willey, J. D.: Organic complexation of $\mathrm{Fe}(\mathrm{II})$ and its impact on the redox cycling of iron in rain, Environ. Sci. Technol., 39(6), 1576-1583, 2005.

Lough, G. C., Schauer, J. J., Park, J. S., Shafer, M. M., Deminter, J. T., and Weinstein, J. P.: Emissions of metals associated with motor vehicle roadways, Environ. Sci. Technol., 39(3), 826-836, 2005.

Majestic, B. J., Schauer, J. J., Shafer, M. M., Turner, J. R., Fine, P. M., Singh, M., and Sioutas, C.: Development of a wet-chemical method for the speciation of iron in atmospheric aerosols, Environ. Sci. Technol., 40, 2346-2351, 2006.

Misra, C., Singh, M., Shen, S., Sioutas, C., and Hall, P. A.: Development and evaluation of a personal cascade impactor sampler (PCIS), J. Aerosol Sci., 33(7), 1027-1047, 2002.

Okada, K., Kuroki, Y., Nakama, Y., Arakaki, T., and Tanahara, A.: Wavelength dependence of $\mathrm{Fe}(\mathrm{II})$ photoformation in the watersoluble fraction of aerosols collected in Okinawa, Japan, Environ. Sci. Technol., 40(24), 7790-7795, 2006.

Papaefthymiou, V., Kostikas, A., Simopoulos, A., Niarchos, D., Gangopadyay, S., Hadjipanayis, G. C., Sorensen, C. M., and Klabunde, K. J.: Magnetic hysteresis and mossbauer studies in ultrafine iron particles, J. Appl. Phys., 67(9), 4487-4489, 1990.

Parkhomenko, V. D., Kolodyazhnyi, A. T., Galivets, Y. D., and Pokholok, K. V.: Mossbauer-spectroscopy applied to surfaces of ultrafine iron powders, Soviet Powder Metallurgy and Metal Ceramics, 29(2), 165-167, 1990.

Pehkonen, S. O., Siefert, R., Erel, Y., Webb, S., and Hoffmann, M. R.: Photoreduction of iron oxyhydroxides in the presence of important atmospheric organic compounds, Environ. Sci. Technol., 27(10), 2056-2062, 1993.

Sheesley, R. J., Schauer, J. J., Hemming, J. D., Geis, S., and Barman, M. A.: Seasonal and spatial relationship of chemistry and toxicity in atmospheric particulate matter using aquatic bioassays, Environ. Sci. Technol., 39(4), 999-1010, 2005.

Singh, M., Jaques, P. A., and Sioutas, C.: Size distribution and diurnal characteristics of particle-bound metals in source and re- 
ceptor sites of the Los Angeles Basin, Atmos. Environ., 36(10), 1675-1689, 2002.

Singh, M., Misra, C., and Sioutas, C.: Field evaluation of a personal cascade impactor sampler (PCIS), Atmos. Environ., 37(34), 4781-4793, 2003.

Torok, S., Faigel, G., Jones, K. W., Rivers, M. L., Sutton, S. R., and Bajt, S.: Chemical characterization of environmental particulate matter using synchrotron-radiation, X-ray Spectrometry, 23(1), 3-6, 1994.

Valavanidis, A., Salika, A., and Theodoropoulou, A.: Generation of hydroxyl radicals by urban suspended particulate air matter. The role of iron ions, Atmos. Environ., 34(15), 2379-2386, 2000.

van Aken, P. A. and Liebscher, B.: Quantification of ferrous/ferric ratios in minerals: new evaluation schemes of $\mathrm{Fe} \mathrm{L}_{23}$ electron energy-loss near-edge spectra, Phys. Chem. Miner., 29, 188-200, 2002.

van Aken, P. A., Liebscher, B., and Styrsa, V. J.: Quantitative determination of iron oxidation states in minerals using $\mathrm{Fe}_{2,3}$ - edge electron energy-loss near-edge structure spectroscopy, Phys. Chem. Miner., 25, 323-327, 1998.
Zaw, M., Szymczak, R., and Twining, J.: Application of synchrotron radiation technique to analysis of environmental samples, Nucl. Instrum. Methods Phys. Res. B, 190, 856-859, 2002.

Zhu, X., Prospero, J. M., Savoie, D. L., Millero, F. J., Zika, R. G., and Saltzman, E. S.: Photoreduction of iron(III) in marine mineral aerosol solutions, J. Geophys. Res., 98(D5), 9039-9046, 1993.

Zhuang, G. S., Yi, Z., Duce, R. A., and Brown, P. R.: Link between iron and sulfur cycles suggested by detection of $\mathrm{Fe}(\mathrm{II})$ in remote marine aerosols, Nature, 355(6360), 537-539, 1992.

Zuo, Y. G. and Deng, Y. W.: Iron(II)-catalyzed photochemical decomposition of oxalic acid and generation of $\mathrm{H}_{2} \mathrm{O}_{2}$ in atmospheric liquid phases, Chemosphere, 35(9), 2051-2058, 1997.

Zuo, Y. G. and Hoigne, J.: Photochemical decomposition of oxalic, glyoxalic and pyruvic-acid catalyzed by iron in atmospheric waters, Atmos. Environ., 28(7), 1231-1239, 1994. 